\title{
Práticas Pedagógicas Interdisciplinares na Licenciatura em Geografia: experiências no cotidiano do fazer geográfico
}

\author{
Interdisciplinary Pedagogical Practices in Higher Education: experiences in the \\ everyday of geographic
}

\section{Prácticas Pedagógicas Interdisciplinares en la Licenciatura en Geografía: experiencias en el cotidiano del hacer geográfico}

\author{
Ana Paula Camilo Pereira ${ }^{1}$ \\ Vera Lúcia Freitas Marinho²
}

\begin{abstract}
RESUMO: A proposta de análise apresentada nesse trabalho se orienta a partir da importância da interdisciplinaridade para além da teoria, concebendo-a na prática pedagógica, a qual nos remete a verificá-la no processo formativo de professores de Geografia. Nessa perspectiva, apresentamos uma metodologia de trabalho executada por meio de ações práticas de interdisciplinaridade no Ensino Superior, mais especificamente do Curso de Licenciatura em Geografia da Universidade Estadual de Mato Grosso do Sul. O objetivo dessas ações interdisciplinares foi promover a articulação e, ao mesmo tempo, contribuir com a desfragmentação entre os saberes geográficos, que historicamente dicotomiza a Geografia Humana e a Geografia Física, num contexto de desarticulação dos saberes preconizada, sobretudo, na formação acadêmica. Desse modo, a importância da interdisciplinaridade não se limita ao ambiente escolar, é preciso que o professor a compreenda em seu processo formativo de modo que a prática interdisciplinar possa ser concebida como possibilidade de rompimento dessa fragmentação. Em síntese, os resultados obtidos a partir dessas experiências pedagógicas são expostos nesse trabalho como possibilidade de propor caminhos alternativos, com novas linguagens que permitam integrar os conhecimentos abordados nos conteúdos disciplinares, na qual a elaboração, o planejamento e a aplicabilidade de experiências interdisciplinares possam somar no cotidiano do fazer geográfico.
\end{abstract}

PALAVRAS-CHAVE: Interdisciplinaridade. Geografia. Práticas interdisciplinares. Formação de professores.

\footnotetext{
${ }^{1}$ Doutorado em Geografia Humana pela Universidade de São Paulo (USP), Doutorado Sanduíche pela Université Sorbonne Nouvelle Paris III, pelo Centre National de la Recherche Scientifique (CNRS). Docente dos cursos de Geografia (Licenciatura e Bacharelado) e do Programa de PósGraduação Stricto Sensu Mestrado Profissional em Educação, ambos da Universidade Estadual de Mato Grosso do Sul (UEMS). Av Dom Antonio Barbosa (MS-080), 4.155. CEP 79115-898, Campo Grande - MS. apaulacape@gmail.com.

2 Doutora em Geografia pelo Instituto de Geociências da Universidade Estadual de Campinas (Unicamp). Docente do curso de Geografia (Licenciatura) da Universidade Estadual de Mato Grosso do Sul (UEMS). Avenida 11 de dezembro, 1425 - Vila Camisão - CEP: 79240-000. Jardim-MS. veramarinho@uems.br.
} 
Práticas Pedagógicas Interdisciplinares na Licenciatura em Geografia: experiências no cotidiano do...

ABSTRACT: The proposal of analysis presented in this work is oriented from the importance of interdisciplinary beyond theory, conceiving it in pedagogical practice, which refers us to verify it in the formative process of teachers of Geography. From this perspective, we present a methodology of work carried out through practical actions of interdisciplinary in Higher Education, specifically of the Degree in Geography of the State University of Mato Grosso do Sul. The objective of these interdisciplinary actions was to promote articulation and, at the same time, to contribute to the defragmentation of geographic knowledge, which historically dichotomizes Human Geography and Physical Geography, in a context of disarticulation of the knowledge advocated, especially in academic formation. Thus, the importance of interdisciplinary is not limited to the school environment, it is necessary for the teacher to understand it in its formative process so that interdisciplinary practice can be conceived as a possibility of breaking this fragmentation. In summary, the results obtained from these pedagogical experiences are presented in this work as a possibility to propose alternative ways, new languages that allow to integrate the knowledge addressed in the disciplinary contents, in which the elaboration, the planning and the applicability of interdisciplinary experiences can add in the of geographic practice.

KEYWORDS: Interdisciplinary. Geography. Interdisciplinary practices. Teacher training.

RESUMEN: La propuesta de análisis presentada en ese trabajo se orienta a partir de la importancia de la interdisciplinaridad más allá de la teoría, la concibiendo en la práctica pedagógica, la cual nos remite a verificarla en el proceso formativo de profesores de Geografía. En esta perspectiva, presentamos una metodología de trabajo ejecutada por medio de acciones prácticas de interdisciplinariedad en la Educación Superior, más específicamente del Curso de Licenciatura en Geografía de la Universidad Estadual de Mato Grosso do Sul. El objetivo de estas acciones interdisciplinares fue promover la articulación y, al mismo tiempo, contribuir con la desfragmentación entre los saberes geográficos, que históricamente dicotomiza la Geografía Humana y la Geografía Física, en un contexto de desarticulación de los saberes preconizada, mayormente en la formación académica. Por lo tanto, la importancia de la interdisciplinariedad no se limita al ámbito escolar, es necesario que el profesor la comprenda en su proceso formativo de modo que la práctica interdisciplinaria pueda ser concebida como posibilidad de rompimiento de esa fragmentación. En síntesis, los resultados obtenidos a partir de esas experiencias pedagógicas se exponen en este trabajo como posibilidad de proponer caminos alternativos, nuevos lenguajes que permitan integrar los conocimientos abordados en los contenidos disciplinarios, en la cual la elaboración, la planificación y la aplicabilidad de experiencias interdisciplinares puedan sumar en el cotidiano del hacer geográfico.

PALABRAS-CLAVE: Interdisciplinariedad. Geografía. Prácticas interdisciplinares. Formación de profesores.

\section{INTRODUÇÃO}

A institucionalização aliada ao avanço da Geografia enquanto ciência produziu, paulatinamente, desde o século XIX, um distanciamento entre a Geografia Física e a Geografia Humana, compreendida como uma dicotomia entre as áreas dessa ciência. Tal processo pode ser visualmente percebido nos cursos de graduação, os quais são definidos por uma espécie de especialização das áreas, muitas vezes observadas até mesmo no corpo docente. 
Essa especialização dedutiva das áreas da Geografia acentua essa ruptura promovendo nos acadêmicos uma identificação única com uma ou outra área. Desse modo, são conduzidos de forma que, muitas vezes, a articulação entre os saberes se dá de forma dissociável na área, ou seja, não há uma assimilação e a Geografia passa a ser compreendida inequivocamente de forma desagregada.

É nesse sentido que buscamos apresentar nesse trabalho uma vertente articuladora, na qual se almeja a superação dessa visão a partir da compreensão de uma totalidade entre a Geografia Física e a Geografia Humana, desprendidas das amarras dicotômicas. Para isso, nos detemos na interdisciplinaridade como um elemento essencial para essa construção desfragmentadora.

Nesse sentido, este trabalho se complementa por seções que buscam nortear a essencialidade de uma ação didático-pedagógica realizada no Ensino Superior, no curso de Licenciatura em Geografia, da Universidade Estadual de Mato Grosso do Sul. O escopo dessa ação teve como prerrogativa impelir uma reflexão associada à execução de uma atividade teórico-prática em que os acadêmicos envolvidos deveriam ter como objeto principal desvelar essa articulação entre a Geografia Física e a Geografia Humana, associando conhecimento físico-natural e humano-social a partir de temáticas arroladas em ambas áreas do conhecimento geográfico, no sentido de evidenciar sua inseparabilidade.

O produto dessas atividades didático-pedagógicas é apresentada nesse trabalho a partir da contextualização do planejamento da ação considerando, nesse caso, a importância da interdisciplinaridade como um arranjo essencial à problematização dessa dualidade. Além disso, destacamos os procedimentos metodológicos dessas ações a partir da elaboração de materiais didático-pedagógicos que são ilustrados nesse trabalho por meio de registros fotográficos das atividades revelando o efeito da dinâmica e da representação dos trabalhos produzidos e utilizados, inclusive pelos próprios acadêmicos em disciplinas práticas, como Estágio Curricular Supervisionado, Didática, Geografia Ambiental e Geografia do Mato Grosso de Sul, Geografia Regional, Geografia Humana e Higrografia, dentre outras.

Os resultados dessas ações são definidas também pelas interpretações dos acadêmicos e dos docentes envolvidos, buscando delinear alguns elementos basilares na praxis didática, ou seja, a adaptação da teoria em prática, enquanto uma ação interdisciplinar que intenta e reforça a necessária relação entre a Geografia Física e Geografia Humana, enquanto totalidade.

Em síntese, o resultado desse trabalho se justifica pela produção deste artigo enquanto registro escrito, no sentido de sujeitar ideias lançadas em nossas práticas docentes cotidianas como contribuições para dialogar, recriar, tensionar e germinar no fazer profissional a criatividade coletiva, contribuindo, dessa forma, com a formação docente dos 
Práticas Pedagógicas Interdisciplinares na Licenciatura em Geografia: experiências no cotidiano do...

acadêmicos, que veem nessas ações possibilidades de articular práticas tradicionais e de exigência curricular com metodologias ativas e dinâmicas, ações afirmativas que concretizam o processo de ensino aprendizagem de forma prazerosa e eficaz. Desse modo, aponta-se nesta proposta o reconhecer da necessidade de realizações de práticas educativas integradas e conjuntas.

\section{O DUALISMO NA CIÊNCIA GEOGRÁFICA: A BUSCA POR AVANÇOS A PARTIR DA INTERDISCIPLINARIDADE}

É importante enfatizarmos que o dualismo entre a Geografia Física e a Geografia Humana e a análise de tal conjunção não se trata de uma abordagem inédita, a intenção, portanto, não é de reprisar essa discussão, mas de acentuar contextualizadamente ações que possam somar para tal desfragmentação.

Mendonça (1998b, p. 154) assevera que essa discussão é "[...] tão velha quanto a própria ciência geográfica moderna [...]", uma vez que existem inúmeras pesquisas que revelam a importância de se romper com esta dicotomia entre a Geografia Física e a Geografia Humana.

A dicotomia tem sua carga histórico-temporal advinda desde o Possibilismo do século XIX, como contraponto aos ditames da corrente Determinista, o que acentuou uma diferenciação combinada a uma especialização entre a Geografia Física e Humana, a qual possibilita análises mais presentes nos elementos humanos em detrimento aos físicosnaturais, exercendo com isso uma predileção. Gradualmente, com o avanço e a sobreposição de novas correntes do pensamento geográfico é possível observar novos contornos a essa dicotomia, mas que, no geral, corroboraram para que a Geografia Física e a Geografia Humana continuassem procrastinadas a uma insensata partição advindas de seus ramos de estudo/análise.

No presente, há uma preocupação com a delimitação e divisão da Geografia em vários setores ou ramos, contudo ainda permanece em evidência um dualismo na Geografia enquanto ciência da natureza ou do ser humano. Conforme destaca Porto Gonçalves (1995, p. 309), ocorreu que na prática "[...] o que os geógrafos fizeram foi reproduzir internamente, no seu meio acadêmico, a dicotomia do pensamento ocidental dominante que separa o homem da natureza".

Nessa abordagem, Pontuschka, Paganelli e Cacete (2009) somam ao reverberarem que na universidade a ciência geográfica ainda é tratada de forma fragmentada, o que pode ser observado nos próprios departamentos. Os autores destacam que esta dicotomia entre geógrafos físicos e geógrafos humanos se aprofunda ainda mais na medida em que 
docentes se aprofundam no conhecimento da climatologia, da geomorfologia, da geografia urbana, da geografia agrária etc.

Outro autor a enfatizar essa fragmentação é Mendonça (1998a). Este ressalta que a Geografia Moderna nasceu com expressiva característica dualista, referindo-se à fragmentação entre a natureza e as dinâmicas da sociedade, e as salas de aula universitárias reforçam esse dualismo. O autor enfatiza ainda que a disparidade de disciplinas que compõem a formação geográfica compromete a busca por uma paradoxal busca de unidade do pensamento geográfico.

Os estudos geográficos que acirram suas especializações a partir de subáreas individualizadas da Geografia caminham de forma muito ambígua, pois muitos geógrafos consagram um ramo dessa ciência, renegando o outro.

Conforme Santos (2016, p. 22), especificamente no transcorrer do século XX, e ainda no presente, observa-se a presença de um modelo fragmentado onde a noção de natureza está separada da noção de sociedade, ou seja, a Geografia Física em contraposição à Humana; "[...] resultando na construção de um olhar em que a humanidade existe sem relevo e o relevo sem a presença das pessoas, construindo-se, portanto, um discurso geográfico que fala de um mundo que não existe de fato, ou que só existiria no plano da imaginação".

Ao refletir sobre a dicotomia entre a Geografia Física e a Geografia Humana, Silva (2007) afirma que, de modo geral, as práticas acadêmicas individualizadas limitam a visão global do objeto de investigação. Além disso, podemos ampliar os objetivos do ensino da Geografia, que conforme Santos (2007, p. 21, grifo nosso) estão além da:

[...] simples apropriação da capacidade de ler e sistematizar graficamente o mundo, desvendando sua geograficidade, ensinar Geografia faz parte, na medida em que possui uma linguagem específica, do esforço de disponibilizar ao educando ferramentas que o ajudem a desenvolver-se cognitivamente. Trata-se, portanto, num plano mais geral, de um grande exercício em busca de ferramentas cognitivas que nos permitam olhar e entender o mundo, ultrapassando os limites da simples sensação e atingindo o nível da cognição.

Dadas tais compreensões sobre essa dicotomia, nossa proposta de análise aqui elaborada se extrai mediante a oportunidade de transpor essa fragmentação, mediante uma proposta e/ou um caminho metodológico. Em outras palavras, apresentamos nesse trabalho uma linguagem interdisciplinar, e sua materialização possibilitou colocar em prática uma ação didático-pedagógica em que os agentes envolvidos conseguiram visualizar pela experimentação que a Geografia Física e a Geografia Humana só podem ser tangíveis se compreendidas em sua totalidade. Com isso, tal materialização, no ensino de Geografia, se 
realizou no sentido de demonstrar que o exercício prático permite ao professor aprimorar sua linguagem e seus conceitos estruturadores por essa totalidade da ciência geográfica.

Ao avançar nessa discussão, passamos para a compreensão da noção de linguagem, que para Santos (2007, p. 21) consiste "[...] um conjunto de símbolos que, usados dentro de determinadas regras, nos permitem construir as mensagens".

Ainda de acordo com Santos (2007, p. 20), ensinar Geografia tendo como ferramenta as linguagens é, portanto, situar: "[...] os modos de pensar desenvolvidos no interior da tradição desse campo do conhecimento: [...] eis, em resumo, o objetivo mais específico que caberia tanto para as séries iniciais do ensino fundamental quanto para o ensino médio ou, mesmo, superior". Conforme Finatti e Ferraz (2011, p. 65):

[...] em cada arranjo societário humano estabelece em seu meio uma linguagem, entendida como o conjunto simbólico-sígnico viabilizador de comunicação e de interpretação de significados necessários para dar sentido ao viver entre os seus membros, além de permitir aos diversos indivíduos entender as regras com as quais cada um se coloca no contexto social.

A Geografia é um conhecimento que faz uso de diversas linguagens para sistematizar suas bases teórico-conceituais, e explicar geograficamente certos fenômenos. Assim, compreende-se que "[...] ensinar Geografia é, sempre, ensinar uma linguagem e, assim, o ensino desse componente curricular (bem como de todas as outras) é, sempre, um processo de alfabetização" (SANTOS, 2007, p. 23).

Nesse sentido, salienta-se que a busca por realizar diferentes metodologias de ensino na Geografia perpassa por essa preocupação, qual seja: prover novas e eficientes linguagens que possibilitem explorar os saberes geográficos em sua totalidade, apresentando-a de forma que favoreça a superação de tal compartimentação. Além disso, o autor questiona: "Será que a dicotomia existente entre a Geografia Física e Geografia Humana não é agravada pelos professores na própria universidade? Como esperar do futuro geógrafo uma visão global da realidade se na própria universidade essa visão não lhe é permitida?" (SILVA, 2007, p. 43).

A preocupação expressa nesse trabalho vem justamente ao encontro da citação destacada. Em outras palavras, buscam-se imprimir uma possibilidade de superar essa fragmentação por meio da interdisciplinaridade e esta se compõe pela articulação do conhecimento geográfico em sua totalidade, a partir do entendimento de que a Geografia é um conhecimento físico-natural e, ao mesmo tempo, humano-social.

A inter-relação entre os conhecimentos, que ainda se constitui fragmentado, se processa na medida em que, para além do campo epistemológico, passamos a materializálo também no campo da prática, uma vez se entende que a prática cotidiana do fazer geográfico envolve e exige uma reflexão sobre a didática promovida em sala de aula, que 
requer análises sobre seus diferentes recursos, discursos, teorias e analogias possíveis, promovendo com isso ações que impigem a resistência dessa indissociabilidade dos saberes geográficos (PEREIRA; CARVALHO; MARINHO, 2016).

Tal necessidade se expressa também nos currículos da Geografia escolar através das práticas espaciais cotidianas as quais configuram um conhecimento cada vez integrado. É nesse contexto que enfatizamos que a importância da interdisciplinaridade não se limita ao ambiente escolar, é preciso que o professor a compreenda em seu processo formativo de modo que a prática interdisciplinar possa ser concebida como possibilidade de construir novos caminhos para o conhecimento, independentemente de qual seja este, por isso a necessidade de rompimento dessa fragmentação.

Em suma, os resultados obtidos a partir dessas experiências pedagógicas são expostos nesse trabalho como possibilidade de propor caminhos alternativos por meio de novas linguagens que permitam integrar os conhecimentos abordados nos conteúdos disciplinares, na qual a elaboração, o planejamento e a aplicabilidade de experiências interdisciplinares possam somar no cotidiano do fazer geográfico.

\section{A PRÁTICA INTERDISCIPLINAR COMO POSSIBILIDADE DE ROMPIMENTO DA FRAGMENTAÇÃO ENTRE GEOGRAFIA HUMANA E GEOGRAFIA FÍSICA}

Como articular as nuances entre a Geografia Física e a Geografia Humana? Como é possível? Por que é necessária esta articulação no Ensino Superior? Como relacionar a teoria e a prática numa esfera fragmentada? Quais os possíveis resultados? As indagações são inúmeras e foi com base em perguntas sem respostas (a priori), que se intentou a busca por produtos e resultados, tendo como prerrogativa principal inserir os acadêmicos em Geografia num processo de ensino-aprendizagem no qual estes próprios pudessem verificar a relação da teoria e da prática por meio da associação entre os saberes geográficos.

A proposta partiu de copiosos diálogos e escritos entre as docentes autoras desse trabalho. Para isso, buscou-se por meio da interdisciplinaridade um caminho didáticopedagógico possível para relacionar atividades correlatas à Ciência Geográfica, reverberando e defendendo a articulação entre diferentes temáticas trabalhadas em disciplinas da área, adstringindo a velha dicotomia existente.

Pontuschka, Paganelli e Cacete (2009, p. 149-150) ao tratarem da interdisciplinaridade a partir de uma leitura crítica sobre os conhecimentos parcelares e as possibilidades de articulação revelam uma abordagem que caminha na perspectiva da totalidade: "[...] o pensar interdisciplinar vai à busca da totalidade na tentativa de articular fragmentos, minimizando o isolamento nas especializações ou dando um novo rumo a elas [...]". 
Práticas Pedagógicas Interdisciplinares na Licenciatura em Geografia: experiências no cotidiano do...

Acrescentamos ainda a compreensão de Fazenda (1979) para quem a interdisciplinaridade é uma nova atitude diante da questão do conhecimento, portanto se coloca como uma ação da prática cotidiana do ato de ensinar e, de acordo com a autora, essa ação se dá por meio de uma profunda imersão no trabalho cotidiano.

Nessa óptica, soma-se ainda Miranda (2008, p. 113), a qual designa ao processo interdisciplinar elementos essenciais para materializá-lo: "[...] tem se constituído como termo polissêmico de estudo, interpretação e ação". Tomamos, nessa analogia, a interdisciplinaridade como estudo no sentido de revelar sua importância e contribuição para a formação docente em Geografia situando-a no contexto da totalidade dos saberes geográficos, de forma a transcender visões ramificadas dessa área.

A interpretação da interdisciplinaridade nos foi depreendida na perspectiva do planejamento interdisciplinar, ou seja, não basta pensar metodologias ativas e englobadoras da totalidade, se não nos atermos a pensar no avanço interdisciplinar por meio de temas, situações-problemas, fatos e fenômenos que revelem mudanças conceituais definidas, sobretudo na realidade cotidiana local, nas abordagens espaciais comuns àqueles que estão envolvidos nesse processo fragmentador, ou seja, os acadêmicos e futuros professores de Geografia. A contextualização do trabalho interdisciplinar tem que ser pensado na articulação entre a teoria e a prática de modo a revelar essa relação na prática diária do educador.

Corroborando com tais questões, destacamos a problemática apontada por Finatti e Ferraz (2011, p. 181), ao considerar a complexidade da realidade atual e o desafio ao ensino de Geografia:

O advento de novas bases técnicas e tecnológicas de acesso e distribuição de informações contribuíram para que as noções de aprendizagem precisassem ser redimensionadas, pois a forma tradicionalmente praticada não estava mais atendendo às necessidades e condições concretamente vivenciadas. Tais aspectos desembocaram na pertinência de valorizar as habilidades, as competências e a interdisciplinaridade como fundamentais no processo de formação das novas gerações.

Desse modo, independentemente da disciplina científica, devemos considerar que fazer o uso do conhecimento científico como elemento importante para o processo de formação das novas gerações cobra um olhar diferenciado e questionador do saber uniformizado e/ou padronizado que, muitas vezes, se faz dominante no mundo acadêmico. Fazenda (1979, p. 56) auxilia nessa perspectiva, ao destacar que:

É necessário, portanto, além de uma interação entre teoria e prática que se estabeleça um treino constante no trabalho interdisciplinar, pois interdisciplinaridade não se ensina, nem se aprende, apenas vive-se, exerce-se. Interdisciplinaridade exige um engajamento pessoal de cada um. 
Todo o indivíduo engajado neste processo será, não só o aprendiz, mas, na medida em que se familiarizar com as técnicas e requisitos básicos 0 criador de novas estruturas, novos conteúdos, novos métodos.

Portanto, a proposta de ação interdisciplinar promovida configurou-se como uma etapa do processo de produção coletiva e metodológica, pensada como uma articuladora de múltiplos saberes disciplinares da área. Nesse sentido, a prática docente foi essencial para que a interdisciplinaridade enquanto estudo-intepretação-ação se constituísse a partir de um conjunto de temas geradores de reflexões conceituais, teóricas e de ações didáticopedagógicas, de forma que orientasse os agentes envolvidos a compreender a indissociável relação entre a Geografia Física e a Geografia Humana.

Em síntese, a prática interdisciplinar nos incita a compreender inúmeros fatores na prática e na teoria da área de Geografia, dos quais destacamos: 1. a importância de se considerar todas os campos disciplinares em sua associação permitindo compreender o conhecimento científico em sua totalidade e não em sua partição; 2. a prática didáticopedagógica na área de Geografia necessita romper com a fragmentação física versus humana, como dois polos isolados por especializações disciplinares; 3. o reconhecimento da interdisciplinaridade pode auxiliar o entendimento entre a articulação dos saberes disciplinares de modo a contribuir com a formação inicial dos professores da área; 4 . é na prática docente do cotidiano que a ação interdisciplinar pode ser explorada e experiencializada a partir do fazer geográfico.

Considerando tais compreensões, e buscando por meio de ações didáticopedagógicas ampliar o debate e promover o transcender entre os conhecimentos fragmentados da Geografia, foi desenvolvido um Projeto de Ensino com o intuito de envolver acadêmicos e docentes na elaboração e produção de materiais didáticos que contribuíssem com leituras desfragmentadoras, buscando extrapolar o dualismo existente por meio da interface entre disciplinas do curso de Geografia. No Quadro 1 apresentamos as etapas que constituíram essas ações, e para a realização dessas atividades apontamos alguns dos procedimentos metodológicos adotados que balizaram este trabalho enquanto projeto teórico e ação prática.

Com base nessas assertivas destacamos a seguir de que modo a interdisciplinaridade foi implementada como prática metodológica na formação de professores de Geografia, ou seja, quais foram os resultados dessa ação na prática cotidiana do processo de ensinoaprendizagem, reconhecendo-os como possibilidades de esforço teórico e prático de relacionar disciplinas do Curso de Licenciatura em Geografia, que historicamente foram estigmatizadas pela dicotomia entre a Geografia Física e Geografia Humana, e como foi possível identificar os avanços do pensar indisciplinar na prática docente, na promoção de ações afirmativas e metodologias ativas. 
Quadro 1 - Práticas pedagógicas interdisciplinares no processo ensino-aprendizagem

\begin{tabular}{|c|c|}
\hline ETAPAS & PROCEDIMENTOS \\
\hline Etapa 1 & $\begin{array}{l}\text { Estudo e planejamento das ações a serem realizadas. Tal etapa foi realizada por meio } \\
\text { da elaboração de um Projeto de Ensino que visava organizar temas geradores na } \\
\text { totalidade das disciplinas, de modo que estes temas geradores pudessem escalonar- } \\
\text { se em diferentes propostas de materiais didáticos, como elaboração de pôsters e/ou } \\
\text { banners com conteúdos escritos e ilustrativos para o ensino de Geografia, } \\
\text { documentários, vídeo-aula, experimentos laboratoriais etc, expostos em espaços da } \\
\text { universidade e nas escolas dos municípios de Jardim e Guia Lopes da Laguna (em } \\
\text { que eram desenvolvidas atividades de estágio pelos acadêmicos); }\end{array}$ \\
\hline Etapa 2 & $\begin{array}{l}\text { Esta etapa foi definida pelos docentes envolvidos no planejamento da ação } \\
\text { interdisciplinar, a qual se constituiu pela seleção de temas geradores e/ou eixos- } \\
\text { chaves para que os acadêmicos pudessem promover suas pesquisas e relacionar } \\
\text { teoria e prática. Nessa seleção de temas consideramos a importância da escala, da } \\
\text { abordagem espacial, trazendo para a prática interdisciplinar a essencialidade de } \\
\text { compreenderem diferentes fenômenos, situações-problemas e fatos a partir da } \\
\text { realidade local, que se constitui na escala regional e estadual de Mato Grosso do Sul. } \\
\text { Os temas geradores e/ou eixos-chaves foram trabalhados de diferentes maneiras, } \\
\text { considerando os mesmos numa perspectiva articulada entre a Geografia Humana e a } \\
\text { Geografia Física; }\end{array}$ \\
\hline Etapa 3 & $\begin{array}{l}\text { Organização dos grupos a partir de temas geradores: foram configurados com o } \\
\text { objetivo de inserir eixos-chaves de conteúdos abordados nas disciplinas e que os } \\
\text { acadêmicos tivessem a possibilidade de se aprofundarem nos temas e ampliar o } \\
\text { levantamento e a sistematização do referencial teórico, bem como a organização } \\
\text { didática dos conteúdos pesquisados, que por fim teriam o objetivo de serem expressos } \\
\text { por um meio de divulgação que favorecesse o processo de ensino-aprendizagem na } \\
\text { prática docente durante a execução da disciplina de Estágio Curricular Supervisionado } \\
\text { no Ensino Básico; }\end{array}$ \\
\hline Eta & $\begin{array}{l}\text { de pesquisa, levantamento bibliográfico e organização do aporte teórico } \\
\text { lanentemente acompanhadas pelas docentes envolvidas, considerando } \\
\text { dução de material didático-pedagógico sobre os temas geradores e/ou } \\
\text { los eixos-chave; }\end{array}$ \\
\hline Etapa 5 & $\begin{array}{l}\text { Posteriormente os grupos elaboraram um resumo expandido sobre os temas } \\
\text { geradores, identificando os aspectos humanos e físicos nos quais exporiam suas } \\
\text { análises de pesquisa, a elaboração de recursos didáticos e a simulação de aula sobre } \\
\text { o trabalho desenvolvido, possibilitando com isso promover um conjunto de ações que } \\
\text { envolveu pesquisa e ensino como possibilidade da prática docente/pesquisador no } \\
\text { ensino de Geografia; }\end{array}$ \\
\hline Etapa 6 & $\begin{array}{l}\text { Esta etapa se consagrou pela apresentação, discussão e avaliação dos trabalhos pelo } \\
\text { público acadêmico, num primeiro momento na sala de aula e, em um segundo } \\
\text { momento, nos espaços abertos da instituição, como forma de expor os resultados dos } \\
\text { produtos finais aos demais acadêmicos, sendo estas últimas etapas consideradas } \\
\text { como produto final da prática interdisciplinar. Para além disso, os acadêmicos } \\
\text { utilizaram os materiais de pesquisa e os recursos didáticos em suas aulas de estágio; }\end{array}$ \\
\hline Etap & $\begin{array}{l}\text { A etapa final foi promovida pelas docentes envolvidas a partir da aplicação de } \\
\text { questionários aos acadêmicos, como forma de compreender os resultados das ações } \\
\text { interdisciplinares, o desenvolvimento das atividades, da produção dos materiais } \\
\text { didáticos e da aplicação dos mesmos em sala de aula. Esta etapa permitiu verificar } \\
\text { como os acadêmicos conseguiram assimilar a importância da interdisciplinaridade para } \\
\text { o rompimento da fragmentação entre a Geografia Física e a Geografia Humana. }\end{array}$ \\
\hline
\end{tabular}

Fonte: Organizado pelas autoras, 2017.

\section{RESULTADOS DA AÇÃO INTERDISCIPLINAR NA PRÁTICA DO FAZER GEOGRÁFICO}

A relação entre o estudo, a interpretação enquanto planejamento e a ação interdisciplinar se realizou por meio da associação dos saberes geográficos. Para isso, 
utilizamos como recorte o Curso de Licenciatura em Geografia da Universidade Estadual de Mato Grosso do Sul - UEMS.

As ideias apresentadas nesse artigo são frutos das ações desenvolvidas mediante três aspectos essenciais à compreensão da Geografia e da formação docente; primeiro: a oportuna precisão de transpor a separação entre Geografia Física e Humana entendendo-as a partir de uma relação de totalidade; segundo: a compreensão da interdisciplinaridade que se confirma na multiplicidade dos saberes integrados, e terceiro: a necessidade de promover a relação teoria e prática, num contexto geográfico que se materializa para além da sala de aula. As atividades interdisciplinares foram realizadas nos anos de 2016 e 2017 e envolveram diferentes disciplinas do campo geográfico, contudo buscamos associá-las em nossas ações teóricas e práticas, como será apresentado a seguir.

As imagens a seguir retratam as possibilidades de compreender a articulação entre a Geografia Humana e Física, por meio da interdisciplinaridade. Estas ações ilustradas a seguir (Figuras 1 e 2) revelam os resultados práticos da pesquisa realizada, da ação disciplinar e dos produtos elaborados, expostos e apresentados na instituição, destacando as temáticas de modo a desenvolvê-las numa perspectiva integradora da Geografia Humana e da Geografia Física, objetivo principal da relação entre as diferentes disciplinas do curso mencionado.

Figura 1 - Atividade interdisciplinar Geografia de Mato Grosso do Sul e Geografia Ambiental - Momento de apresentação e avaliação - Exposição de Pôster

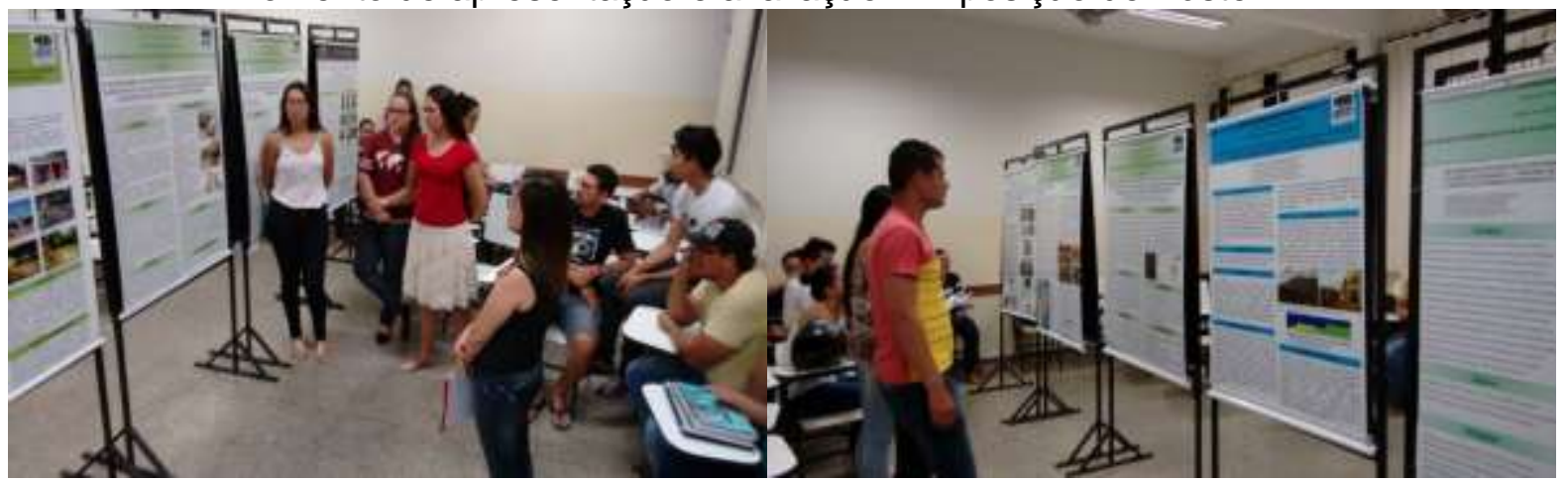

Fonte: arquivo pessoal das autoras, 2017.

Todas as fases de execução dos trabalhos foram observadas conjuntamente e computadas no processo avaliativo, o que implica na necessidade de ressaltar as possibilidades abertas de ser professor/pesquisador e, dessa forma, permite outras formas de conceber didaticamente o ensino na formação do professor.

Para além dos resultados internos à dinâmica interdisciplinar realizada, alguns trabalhos elaborados foram selecionados para apresentação em um evento científico, o Encontro de Ensino, Pesquisa e Extensão (ENEPEX), organizado e realizado pela instituição e demais instituições públicas de Ensino Superior do estado de Mato Grosso do 
Sul, na cidade de Aquidauana, no estado de Mato Grosso do Sul, conforme ilustrado na Figura 3. Tal fato ressaltou a importância dessa ação interdisciplinar e possilitou aos acadêmicos apresentarem seus trabalhos em um evento científico, promovendo mais uma vez a integração entre o ensino e a pesquisa.

Figura 2 - Exposição de pôsters da turma do $4^{\circ}$ ano - Atividade final das disciplinas Geografia de Mato Grosso do Sul e Geografia Ambiental
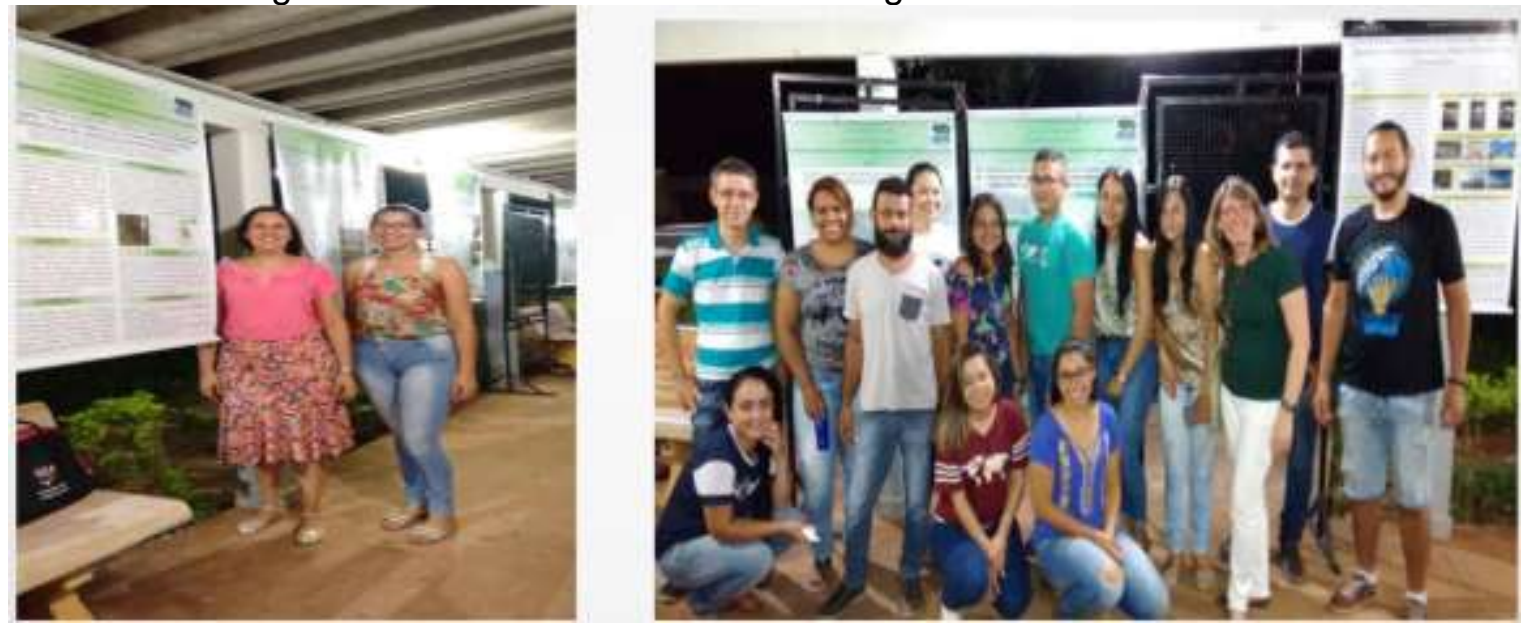

Fonte: arquivo pessoal das autoras, 2017.

Figura 3 - III ENEPEX - Encontro de Ensino, Pesquisa e Extensão.

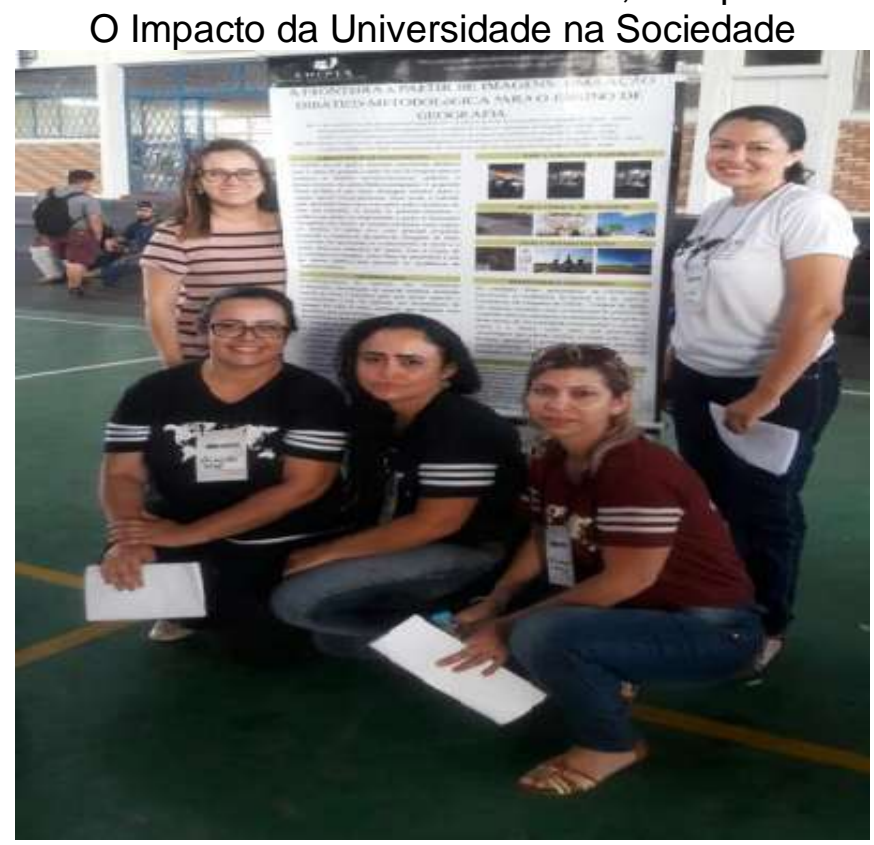

Fonte: arquivo pessoal das autoras, 2017.

Além da prática interdisciplinar destacada acima, foi realizada ainda outras ações com a mesma finalidade. Entre os resultados obtidos, destacamos a realização de um evento científico organizado pelas autoras, o EXPOGEO (Exposição de Práticas e Material Didático para o Ensino de Geografia), o qual resultou em um Projeto de Extensão. A proposta teve 
como objetivo a produção e a exposição do material didático-pedagógico realizado pelos acadêmicos como requisito de cumprimento das disciplinas de Geografia Ambiental, Fundamentos da Pedologia, Biogeografia, Estágio Curricular Supervisionado II, Fundamentos de Geologia e Fundamentos de Hidrologia.

Nessa ocasião, foram expostos materiais didáticos elaborados pelos acadêmicos como: maquetes, jogos interativos, produção de painéis interativos, apresentação e manuseio de acervo geológico, produção e observação de lâminas com conteúdo fóssil, dentre outros, considerando temas diversos, os quais foram expostos nos corredores da instituição.

A ideia possibilitou aprofundar o diálogo entre as diferentes disciplinas do curso e promover uma aproximação dos acadêmicos das escolas junto à Universidade, no sentido de tornar esse evento um veículo plural, democrático e aberto à comunidade. Conforme consta na Figura 4, os materiais didáticos elaborados pelos acadêmicos foram disponibilizados para outras atividades de ensino de Geografia, e outros foram doados às escolas públicas participantes do evento.

Figura 4 - Produção de material didático-pedagógico - Maquete de Bacia Hidrográfica

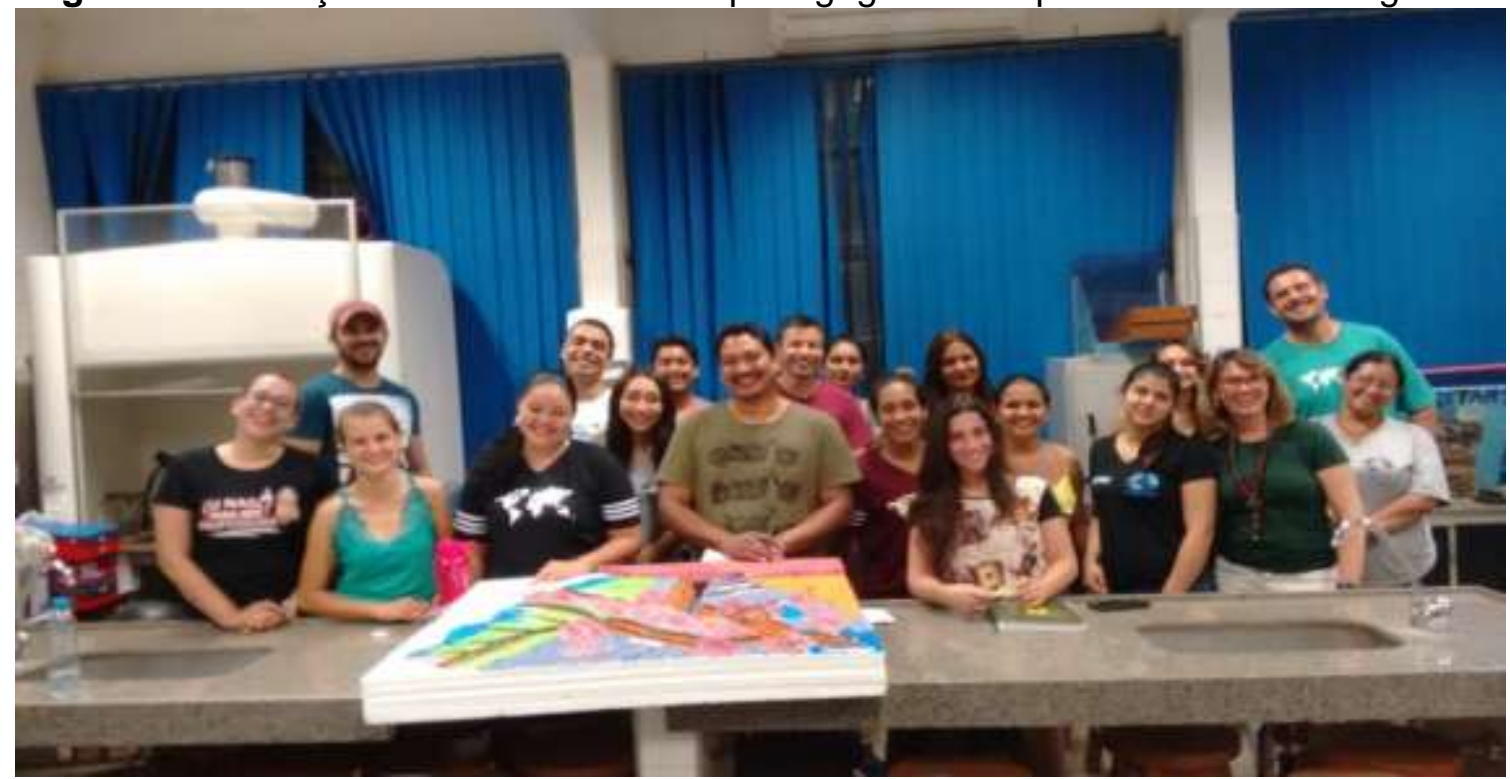

Fonte: arquivo pessoal das autoras, 2017.

Além disso, outra atividade de material didático-pedagógico sugerida foi a elaboração e a apresentação de diversos vídeos documentários produzidos pelos acadêmicos sobre temáticas variadas, com foco na natureza e na sociedade a partir de um olhar crítico sobre as diferentes perspectivas de análise.

Essa atividade tinha como objetivo analisar os solos no espaço regional em que foi desenvolvido o projeto e articular os tipos de solos com as produções agrícolas existentes, compreendendo a forma de produção com o perfil de solo. Além disso, buscou-se produzir 
material didático-pedagógico, desenvolver e apresentar experiências de ensino de solos, incluindo o plano de aula e o relatório de avaliação da atividade. Esta experiência foi organizada com apoio do projeto de ensino: Experimentoteca de Solos - Projeto Solo na Escola o qual apresenta uma proposta metodológica voltada para auxiliar o ensino de solos nos níveis fundamental e médio. A Figura 5 destaca na primeira imagem a produção de vídeo sobre a elaboração de perfil de solo e na segunda imagem a produção de vídeo referente a coleção de cores de solo.

Figura 5 - Produção de vídeo como material didático-pedagógico - elaboração de perfil de solo e - elaboração coleção de cores de solos
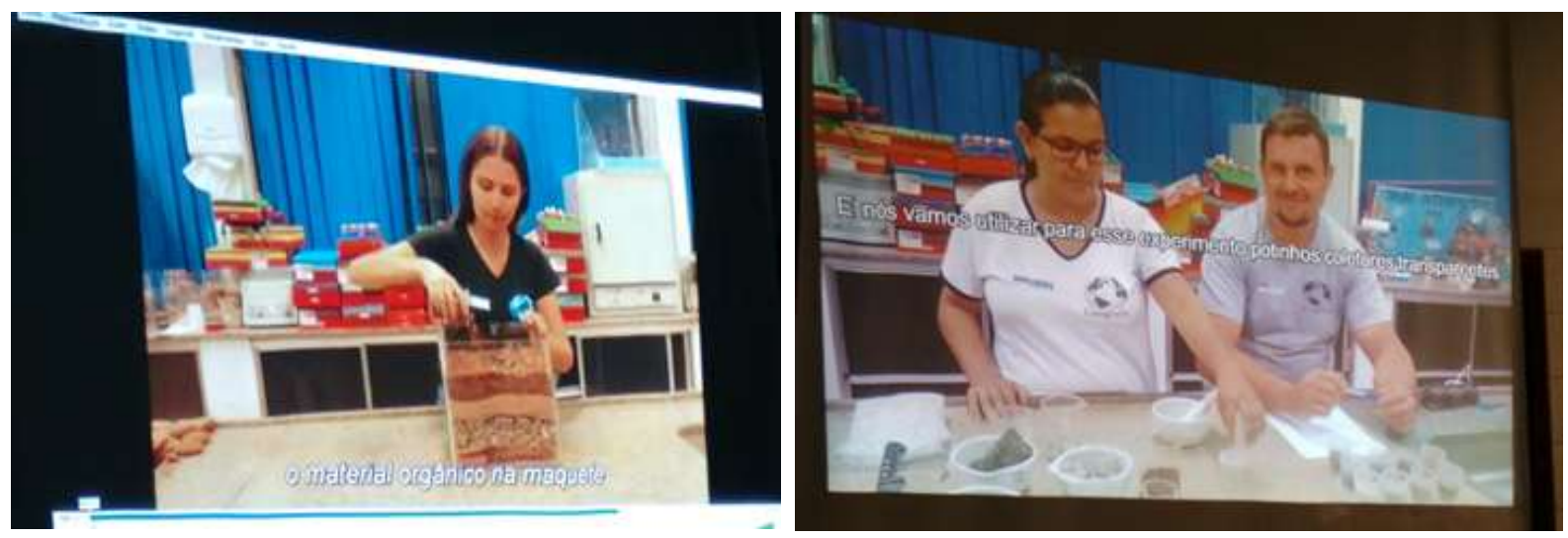

Fonte: arquivo pessoal das autoras, 2017.

Tal experiência visou aproximar o conteúdo teórico das práticas didático-pedagógicas. Os procedimentos adotados se constituíram pela formação de grupos de trabalho, divididos por temas relacionados ao ensino de solos. No total foram propostos 10 temas. Cada grupo ficou responsável por elaborar as experiências práticas e gravar o vídeo no formato de aulas, conforme um plano de aula a ser entregue no dia da apresentação. Além das vídeoaulas, os acadêmicos apresentaram os conteúdos propostos e relatórios contendo o processo no desenvolvimento da atividade. As fotos se referem aos dois momentos dessa atividade, um primeiro grupo trabalhou o tema sobre os horizontes dos solos; enquanto o segundo grupo apresentou a coleção de cores de solos - denominada de colorteca. Muitas dessas experiências foram transformadas em artigos e apresentadas no evento científico supracitado.

Ainda dentro da perspectiva do estudo-planejamento-ação da interdisciplinaridade, as docentes executadoras desse projeto elaboraram um questionário que foi aplicado aos acadêmicos que realizaram os trabalhos. O objetivo foi reconhecer a partir da oralidade destes a importância da interdisciplinaridade e da produção e aplicabilidade do material didático em suas aulas de estágio como um elemento de contribuição ao processo de ensino-aprendizagem dos alunos do Ensino Básico. Com isso, buscou-se ainda por meio 
desse questionário identificar o resultado dessa ação na promoção à articulação entre os saberes dicotômicos da Geografia.

Os resultados, conforme as respostas das avaliações aplicadas aos acadêmicos revelaram posicionamentos substanciais à continuidade dessas ações, uma vez que enfatizaram a essencialidade e a contribuição da interdisciplinaridade na formação docente e para a desfragmentação dos saberes geográficos.

O questionário tinha como prerrogativa principal verificar qual a importância da interdisciplinaridade, da ação realizada e de como tal prática didático-pedagógica contribui com a formação do acadêmico enquanto um futuro profissional licenciado em Geografia. $O$ Quadro 2 apresenta uma sistematização das respostas obtidas a partir dos questionários aplicados aos acadêmicos que participaram do projeto de ensino.

Em síntese, o desenvolvimento desse projeto contribuiu de inúmeras formas. Primeiro, o resultado teórico-prático com os acadêmicos do curso de Licenciatura em Geografia se define pela compreensão dos mesmos sobre a necessidade e a importância de se desconstruir a dicotomia entre a Geografia Humana e a Geografia Física. Segundo, foi possível trabalhar essa questão na prática ao promovermos a interdisciplinaridade no curso, permitindo aos acadêmicos realizarem análises sobre um mesmo tema na duas perspectivas, ou seja, com um olhar geográfico integrador e totalizador.

Por fim, o resultado da elaboração de material didático (banner, vídeo-aulas, documentários e análises laboratoriais) e a exposição dos mesmos nos espaços abertos da universidade e nos estágios curriculares dos acadêmicos nas escolas se constituíram como produtos eficazes no processo de ensino-aprendizagem, demonstrando a contribuição dessa ação interdisciplinar no processo formativo dos acadêmicos enquanto futuros professores de Geografia, o que nos fora demonstrado a partir das respostas dos acadêmicos aos questionários aplicados e também nas orientações e debates sobre suas práticas disciplinares no Ensino Básico. 
Quadro 2 - Resultados dos questionários aplicados no Projeto de Ensino

\begin{tabular}{|c|c|}
\hline $\begin{array}{l}\text { GRUPOS DE } \\
\text { ACADÊMICOS }\end{array}$ & RESPOSTAS \\
\hline Grupo de Acadêmicos 2 & $\begin{array}{l}\text { [...] é muito importante a produção e a utilização do material didático, } \\
\text { pois facilita a aprendizagem de maneira que possibilita organizar o } \\
\text { conteúdo/tema a ser apresentado, podendo ser utilizado como uma } \\
\text { ferramenta didático-pedagógica tanto para a apresentação em } \\
\text { eventos científicos, quanto para trabalhar na Educação Básica, } \\
\text { possibilitando a troca de conhecimento. Permite trabalhar na prática } \\
\text { toda a teoria que aprendemos ao longo do curso de Geografia, além } \\
\text { de promover a dinamização nas aulas e envolver os alunos de modo } \\
\text { a promover neles um olhar geográfico para o meio em que estão } \\
\text { inseridos, podendo compreender os elementos humanos e naturais } \\
\text { em articulação, principalmente considerando a nossa realidade local, } \\
\text { o que facilita, ao mesmo tempo, aprender e ensinar, pois estamos } \\
\text { aprendendo conteúdos teóricos que explicam o nosso espaço } \\
\text { regional. }\end{array}$ \\
\hline Grupo de Acadêmicos 1 & $\begin{array}{l}\text { [...] a utilização do banner, dos vídeos, dos experimentos como } \\
\text { recursos didáticos destacam-se pela associação entre o conteúdo } \\
\text { teórico e as imagens, buscando com isso aproximar e instigar nos } \\
\text { estudantes uma forma de conhecimento prático sobre suas realidade } \\
\text { cotidianas, isso é importante para o processo de ensino- } \\
\text { aprendizagem mais prazeroso e eficaz. [...]. Não precisa ser } \\
\text { necessariamente um banner, podemos elaborar cartazes com } \\
\text { figuras, textos e imagens que podem, por sua vez, serem expostos } \\
\text { em forma de seminários ou nos corredores das escolas. Isso } \\
\text { contribui tanto para ensinar como para aprender Geografia de forma } \\
\text { mais didática, dinâmica e diferenciada, pois extrapola a rotina de } \\
\text { fazer e utilizar sempre os mesmos métodos de ensino. }\end{array}$ \\
\hline Grupo de Acadêmicos 5 & $\begin{array}{l}\text { [...] essa experiência de produzir material didático para aplicar em } \\
\text { nossas aulas de estágio é uma forma de apresentação e explicação } \\
\text { do conteúdo que permite associar Geografia Humana e Geografia } \\
\text { Física, sem vê-las de forma separadas, fragmentadas. Essa } \\
\text { metodologia nos deu uma bagagem para além do conhecimento } \\
\text { teórico específico do curso de Geografia, pois podemos aprimorar os } \\
\text { métodos de ensino e aprendizagem, melhorando a didática em sala } \\
\text { de aula, além de nos possibilitar a elaboração de trabalhos } \\
\text { científicos para serem apresentados em eventos. Expor o banner e } \\
\text { os vídeos para o Ensino Básico trouxe a condição de apresentar o } \\
\text { conteúdo de forma mais articulada à realidade local, demonstrando a } \\
\text { relação entre os aspectos físicos e os aspextos humanos. }\end{array}$ \\
\hline
\end{tabular}

Fonte: Relatório dos questionários aplicados aos acadêmicos, 2017.

\section{CONSIDERAÇÕES FINAIS}

O desenvolvimento dessas atividades gerou conhecimento e envolvimento dos acadêmicos e da equipe de execução, bem como possibilitou divulgar à comunidade externa algumas das abordagens de ensino realizadas na capacitação dos acadêmicos do curso de Geografia. As contribuições são para além da sala de aula, e resultaram na integração entre as áreas do conhecimento, bem como evidenciou a importância da interdisciplinaridade na execução de projetos de pesquisa, extensão e ensino - tripé necessário na para promover uma formação social e humana de qualidade. E, ainda, destaca-se que outros resultados 
foram gerados como as produções técnico-científicas apresentadas e publicadas em eventos científicos.

Nas discussões realizadas nos momentos de avaliações dos acadêmicos percebemos a importância da integração das práticas propostas para formação profissinal, no entanto também reconhecemos a barreira que se faz presente para integrar as áreas de conhecimento, sendo esta uma lacuna na formação a ser superada no processo de formação dos professores de Geografia no Ensino Superior.

Para não concluir, enfatizamos que não temos a pretensão de aprofundar as discussões teóricas, mas essencialmente expressar, conforme as experiências práticas acima apresentadas neste trabalho, que o intuito está em sinalizar e buscar caminhos alternativos e novas linguagens que permitam integrar na pesquisa, ensino e extensão os conhecimentos abordados nos conteúdos repassados aos acadêmicos na formação de professor de Geografia.

De tudo que podemos destacar, nossa única e evidente conclusão é que a prática interdisciplinar é uma possibilidade de se promover a compreensão da articulação dos saberes na Geografia, de modo que formemos professores para a educação geográfica, isentos da fragmentação ou da dicotomia do conhecimento na área de Geografia.

\section{REFERÊNCIAS}

FAZENDA, I. C. A. Integração e interdisciplinaridade no ensino brasileiro: efetividade ou ideologia? São Paulo: Loyola, 1979.

FINATTI, R.; FERRAZ; C. B. O. Linguagem geográfica do jogo de xadrez: uma aproximação ao conceito de território e ao processo de ensino-aprendizagem. In: NUNES; F. G. (Org.).

Ensino de geografia: novos olhares e práticas. Dourados, MS: UFGD, 2011. p. 61-101.

MENDONÇA, F. Dualidade e dicotomia da geografia moderna. Ra'EGA: o Espaço Geográfico em Análise, Curitiba, v. 2, n. 2, p. 153-165, 1998a.

MENDONÇA, F. Geografia física: ciência humana? São Paulo: Contexto, 1998b.

MIRANDA, R. G. Da interdisciplinaridade. In: FAZENDA, I. C. A. (Org.). O que é interdisciplinaridade? São Paulo: Cortez, 2008. p. 113-124.

PEREIRA, A. P. C.; CARVALHO, P. A.; MARINHO, V. L. F. A interdisciplinaridade e a indissociável relação teoria-prática: a materialização de trabalho de campo na formação docente e no ensino de geografia. In: SEMINÁRIO INTERNACIONAL DA AMÉRICA PLATINA, 6., COLÓQUIO UNBRAL DE ESTUDOS FRONTEIRIÇOS, 1., 2016, Campo Grande-MS. Anais... Campo Grande: UEMS, 2016. Disponível em:

<http://eventos.sistemas.uems.br/assets/uploads/eventos/88a59795508e69486b5c940014aff e2c/anais/4_2016-11-13_13-13-14.pdf>. Acesso em: 10 fev. 2017.

PONTUSCHKA, N. N.; PAGANELLI, T. I.; CACETE, N. H. Para ensinar e aprender Geografia. São Paulo: Cortez, 2009. 
PORTO GONÇALVES, C. W. Formação sócio-espacial e questão ambiental no Brasil. In: BECKER, B. K. et al. (Org.). Geografia e meio ambiente no Brasil. São Paulo: Hucitec, 1995, p. 309-333.

SANTOS, D. O ensino da Geografia e o direito à escola e ao conhecimento. São Paulo: [S. n], 2016.

SANTOS, D. O que é geografia? 2007. Apostila.

SILVA, S. H. P. Geografia Física e Geografia Humana: uma dicotomia a ser superada? Outros Tempos, Maranhão. v. 4, n. 4, p. 40-49, 2007.

Recebido: abril de 2018. Aceito: junho de 2018. 